\title{
Annexin A5 Increases Survival in Murine Sepsis Model by Inhibiting HMGB 1-Mediated Proinflammation and Coagulation
}

\author{
Jung Hwa Park, ${ }^{1}$ Jong-Hwa Jang, ${ }^{2}$ Eun Jung Choi, ${ }^{1}$ Young Seob Kim, ${ }^{1}$ Eun Ji Lee, ${ }^{1}$ In Duk Jung, ${ }^{1}$ \\ Hee Dong Han, ${ }^{1}$ T-C Wu, ${ }^{3,4,5,6}$ Chien-Fu Hung, ${ }^{3,6}$ Tae Heung Kang, ${ }^{1 *}$ and Yeong-Min Park ${ }^{1^{*}}$
}

${ }^{1}$ Department of Immunology, KU Open Innovation Center and School of Medicine, Konkuk University, Chungju, South Korea; ${ }^{2}$ Department of Dental Hygiene, Hanseo University, Seosan, South Korea; ${ }^{3}$ Department of Pathology, Johns Hopkins Medical Institutions, Baltimore, MD, United States of America; ${ }^{4}$ Departments of Obstetrics and Gynecology, Johns Hopkins Medical Institutions, Baltimore, MD, United States of America; ${ }^{5}$ Department of Molecular Microbiology and Immunology, Johns Hopkins Medical Institutions, Baltimore, MD, United States of America; and ${ }^{6}$ Department of Oncology, Johns Hopkins Medical Institutions, Baltimore, MD, United States of America

\begin{abstract}
The identification of HMGBI as a late mediator in sepsis has highlighted HMGB1 as a promising therapeutic target for sepsis treatment. Recent studies have revealed that annexin A5, a $35 \mathrm{kDa} \mathrm{Ca}{ }^{2+}$-dependent phospholipid binding protein, exerts antiinflammatory effect by inhibiting LPS binding to TLR4/MD2 complex. Annexin A5 administration has been shown to protect against endotoxin lethality even when the treatment was given after the early cytokine response, which prompted our group to suspect that annexin A5 may inhibit the binding of HMGB1, as well as endotoxin, to TLR4. Here we suggest annexin A5 as a new inhibitor of HMGB1-mediated proinflammatory cytokine production and coagulation in sepsis. We first confirmed the inhibitory role of annexin A5 in LPS-induced production of proinflammatory cytokines both in vitro and in vivo. We observed that annexin A5 protects against tissue damage and organ dysfunction during endotoxemia in vivo. We then assessed the inhibiting role of annexin A5 in HMGB1/TLR4 interaction, and showed that annexin A5 treatment reduces HMGB1-mediated cytokines IL6 and TNF $\alpha$ both in vitro and in vivo. Finally, we confirmed that anticoagulant property of annexin A5 persists in various septic conditions including elevated HMGB1. Overall, we suggest annexin A5 as an alternative therapeutic approach for controlling HMGB1-mediated proinflammation and coagulation in patients with sepsis.
\end{abstract}

Online address: http://www.molmed.org

doi: $10.2119 / \mathrm{molmed} .2016 .00026$

\section{INTRODUCTION}

Sepsis is a life-threatening clinical syndrome resulting from the excessive proinflammatory cytokine response to infection combined with coagulopathy. Over 200,000 people die from sepsis each year, which is more than the number of deaths caused by HIV, breast cancer or stroke $(1,2)$.

When a pathogen invades a human body, toll-like receptors on the sentinel cells promptly recognize pathogenassociated molecular patterns (PAMPs), and subsequently initiate the first line of

*JHP and J-HJ contributed equally to this work and should be considered co-first authors. Address correspondence to Tae Heung Kang, Department of Immunology, School of Medicine, Konkuk University, 268 Chungwon daero, Chungju, South Korea. Tel: 82-2-2049-6089; Fax: 82-2-2049-6195; E-mail: kangiron@kku.ac.kr; or Yeong-Min Park, Department of Immunology, School of Medicine, Konkuk University, 268, Chungwondaero, Chungju, South Korea. Tel: 82-2-2049-6158; Fax: 82-70-8280-0378; E-mail: immun3023@kku.ac.kr. Submitted January 27, 2016; Accepted for publication June 29, 2016; Published Online (www.molmed.org) July 6, 2016

I

Feinstein Institute for Medical Research Northwell Health

defense $(3,4)$. In particular, the toll-like receptor 4 (TLR4) expressed on dendritic cells is responsible for detecting the presence of lipopolysaccharides (LPS), a cell wall component in gram-negative bacteria (5). Formation of LPS-TLR4/ MD2 complex leads to the recruitment of MyD88 and TRIF, which in turn trigger mitogen-activated protein kinases (MAPKs). TLR4 signaling promotes the gene expression of proinflammatory cytokines, such as TNF- $\alpha$ and IL-6, within minutes after LPS exposure $(4,6,7)$. Excessive production of these cytokines by immune cells results in cytokine storm, which induces tissue damage and organ dysfunction, the consequence of which is called severe sepsis (8).

Clinical trials of early sepsis mediatortargeted therapies have demonstrated limited success due to their narrow 
therapeutic windows, which directed new attention toward late-acting mediators such as high-mobility group box 1 protein (HMGB1) $(6,9)$. HMGB1 is a highly conserved non-histone DNA binding nuclear protein, functioning as a damage-associated molecular pattern (DAMP) upon release by dying cells or activated immune cells (10-12). Once emitted into extracellular milieu, HMGB1 physically interacts with various receptors in immune cells. In particular, binding of HMGB1 to TLR4/MD2 complex plays a critical role in cytokine production $(13,14)$. HMGB1-mediated proinflammatory cytokine production may further deteriorate organ dysfunction, and it has been established that the control of HMGB1 is crucial in the management of sepsis $(6,15,16)$.

HMGB1-specific neutralizing antibodies were shown to be successful in controlling sepsis in animal models, which led to further development of methods to antagonizing HMGB1 (6,16-19). Many of these therapeutic strategies focused on the attenuation of HMGB1-mediated proinflammatory response. However, recent studies have revealed that in addition to mediating late stage-inflammatory response by immune cells, HMGB1 signaling in platelets play a critical role in thrombus formation and other hyper-coagulation processes, which exacerbates tissue damage and aggravates severe sepsis $(11,12,20-22)$. In clinic, the serum level of HMGB1 and prognosis of organ failure appeared to be positively correlated in a septic patient with disseminated intravascular coagulopathy (DIC) (23).

Annexin A5, or the human placental anticoagulant protein-I (PAP-I), is a $35 \mathrm{kDa}$ $\mathrm{Ca}^{2+}$-dependent phospholipid binding protein (5). Annexin A5 is known to bind to exposed phosphatidylserine on the platelet, and withholds further aggregation and coagulation processes by forming a protective 2-Dimensional (2D) crystallized shield over the platelet surface $(5,24-27)$. Several groups have recently demonstrated that annexin A5 exerts an antiinflammatory effect through inhibiting LPS binding to
TLR4/MD2 receptor $(5,27,28)$. The therapeutic potential of annexin A5 in sepsis has mainly been investigated by examining the role of annexin A5 as an endotoxin inhibitor $(5,28)$. The capacity of annexin A5 to block TLR4/MD2 signaling prompted us to question whether annexin A5 can also antagonize the interaction between HMGB1 and TLR4/MD2.

In this study, we hypothesized that annexin A5 can block the binding of HMGB1 to TLR4/MD2, and lead to changes in two major aggravating factors in sepsis, including (a) suppression of HMGB1-mediated proinflammatory response in immune cells and (b) alleviation of the pro-coagulant condition initiated by HMGB1. We found that annexin A5 has a protective effect in polymicrobial sepsis and late treatment endotoxin models as well as LPS-induced sepsis models by inhibiting HMGB1 functions. Overall, our study revealed a therapeutic role of annexin A5 in sepsis by inhibiting HMGB1-mediated proinflammation and coagulation responses.

\section{MATERIALS AND METHODS}

\section{Animals}

Six-to-eight-week-old 16-18 g female C57BL/6 mice were purchased from the Orient Bio Inc. All animal studies were performed according to approved protocols by the Institutional Animal Care and Use Committee (IACUC) of the Konkuk University (Permit Number: KU15058) and in accordance with recommendations for the proper use and care of the specific pathogen-free housing facility at the Konkuk University. By survival studies, humane endpoints were used to minimize suffering. In case clinical signs of the moribund state were recognized, the animals were euthanized by $\mathrm{CO}_{2}$ euthanasia (29). The signs of the moribund state included impaired mobility (unable to reach food and water), inability to maintain upright position, prolonged lack of activity and labored breathing (29). As soon as such signs had been observed, the animals were placed in the $\mathrm{CO}_{2}$ chamber, and low flow of $\mathrm{CO}_{2}$ gas was administered. One hundred percent
$\mathrm{CO}_{2}$ gas was administered for another 5 min after animals lost consciousness. All intraperitoneal injections, sacrifices for organ removal and tail bleeding assays were performed under isoflurane anesthesia. Experimental animals were allowed to inhale isoflurane with $100 \% \mathrm{O}_{2}$ gas for $60 \mathrm{~s}$ to minimize suffering.

\section{DNA Constructs and Protein Preparation}

pET28a-annexin A5 was constructed by Polymerase Chain Reaction (PCR) using template annexin A5 (Addgene) and primers TTTGG ATCCA TGGCA CAGGT TCTCA GAGG and AAAGA ATTCG TCATC TTCTC CACAG AGCA (Cosmo Genetech Co.). The PCR fragment was cloned into BamHI and EcoRI sites of the PET28a vector. pET28a-annexin A5 plasmids were transformed into the competent BL21(DE3) Escherichia coli strain (NEB). Protein expression was induced by $1 \mathrm{mmol} / \mathrm{L}$ isopropyl-b-D-thiogalactopyranoside (IPTG) (Bio Basic Inc.) at $37^{\circ} \mathrm{C}$ for $5 \mathrm{~h}$. The cultured cells were harvested by centrifugation and the pellet was lysed in the SoluLyse buffer (Genlantis) for bacterial protein extraction containing lysozyme (100 $\mu \mathrm{g} / \mathrm{mL})$ (Gibco BRL), $5 \mathrm{mmol} / \mathrm{L}$ DTT (Bio Basic Inc.) and deoxynuclease I (200 U/mL) (Invitrogen). The suspension was incubated at room temperature for $2 \mathrm{~h}$ and centrifuged at $10,000 \mathrm{~g}$ for $10 \mathrm{~min}$. The lysate was purified by $\mathrm{Ni}^{+}$affinity chromatography with Ni-NTA agarose (Qiagen) according to the manufacturer's protocol. The eluted protein was concentrated with $10 \mathrm{~K}$ centrifugal filter devices (MerckMillipore). The concentrated protein analyzed using $12 \%$ gradient SDSPAGE gels and Coomassie Brilliant Blue staining, and anti-annexin A5 antibody (abcam). Endotoxin was removed from purified proteins by using Triton X-114 Surfact-Amps detergent (Thermo Scientific). Endotoxin level (less than $0.1 \mathrm{EU} /$ mg protein), and the level of bacterial DNA (0.1 ng/mg protein) were assessed using Limulus amoebocyte lysate (LAL) QCL-1000 (LONZA Ltd.) and Picogreen 
assays (Invitrogen), respectively. Protein concentrations were determined by a Bradford protein assay kit (Thermo Scientific).

\section{LPS-Induced Endotoxemia Model}

Mice were intraperitoneally injected with $50 \mathrm{mg} / \mathrm{kg}$ of LPS (E. coli serotype O127:B8) (Sigma) dissolved in Phosphate buffered saline (PBS). Each mouse was intravenously injected with $500 \mu \mathrm{g}$ annexin A5 protein dissolved in $100 \mu \mathrm{L}$ PBS as indicated.

\section{Cecal Content Injection (CCl)-Induced Sepsis Model}

Cecal content injection-induced sepsis models were generated as previously described (30). After being euthanized by $\mathrm{CO}_{2}$ inhalation, cecectomy was performed and the cecal contents were extruded with a cotton swab into a Petri dish. PBS was added to a final concentration of $20 \mathrm{mg} / \mathrm{mL}$, which was then minced using ground glass. Mice were intraperitoneally injected with $1 \mathrm{~mL}$ of homogenized cecal contents. Each mouse was intravenously injected with $500 \mu \mathrm{g}$ annexin A5 (in $100 \mu \mathrm{L}$ PBS) concurrently with CCI challenge.

\section{Isolation of Bone Marrow-Derived Dendritic Cell}

Monocytes were isolated from the bone marrow of C57BL/ 6 mice, which were then cultured in the RPMI 1640 medium (Biowest) supplemented with $10 \%$ fetal bovine serum, $50 \mathrm{U} /$ $\mathrm{mL}$ penicillin/streptomycin, $2 \mathrm{mmol} / \mathrm{L}$ L-glutamine, $1 \mathrm{mmol} / \mathrm{L}$ sodium pyruvate, $2 \mathrm{mmol} / \mathrm{L}$ nonessential amino acids, $10 \mathrm{ng} / \mathrm{mL}$ granulocyte-macrophage colonystimulating factor (GM-CSF) (Peprotech) and $5 \mathrm{ng} / \mathrm{mL}$ IL4 (Peprotech) at $37^{\circ} \mathrm{C}$ with $5 \% \mathrm{CO}_{2}$. The monocytes were incubated for $6 \mathrm{~d}$ before being used in the experiment.

\section{TLR Signaling-Related Reagents}

Lipopolysaccharides obtained from E. coli O111:B4, Pam3CSK4, Poly(I:C), Imiquimod, ODN1826 and MAb mTLR4/MD2 were all purchased from InvivoGen. Human HMGB1 (His tag) was purchased from Sino Biological Inc.

\section{Flow Cytometry}

Dendritic cells were stained with a Fluorescein isothiocyanate (FITC)-conjugated CD11c DC surface antibody, Phycoerythrin (PE)-conjugated CD40, CD80 and CD86 (Biolegend) DC maturation antibodies, respectively. T cells were stained with an APC anti-mouse CD3 (Biolegend), and analyzed using FACS Calibur cytometry with BD CELL Quest Pro software.

\section{Cytokine Level Measurements}

The concentrations of proinflammatory cytokines IL6, TNF $\alpha$, IL10 and HMGB1 in cell supernatants or serum were quantified by using commercially obtained enzyme-linked immunosorbent assay (ELISA) kits. The ELISA kits for measurement of IL6, TNF $\alpha$ and IL10 were all purchased from eBioscience. The ELISA kits for measurement of HMGB1 were purchased from Sino Biological Inc. The Elisa kits for measurement of total protein $\mathrm{C}$ and tissue factor is purchased from Cusabio

Biotech Co. Each assay was carried out according to the instructions provided by the manufacturer.

\section{Western Blot Analysis}

Bone marrow dendritic cells $\left(4 \times 10^{6}\right)$ were incubated with LPS (50 ng/mL) with or without annexin A5 protein $(20 \mu \mathrm{g} / \mathrm{mL})$ for $0,10,30,60$ or $120 \mathrm{~min}$. Cells were scraped, washed, centrifuged and resuspended on ice in the RIPA protein extraction solution $(50 \mathrm{mmol} / \mathrm{L}$ Tris-Cl [pH 8.0], $150 \mathrm{mmol} / \mathrm{L} \mathrm{NaCl}$, $1 \mathrm{mmol} / \mathrm{L}$ phenylmethylsulphonyl fluoride [PMSF], 0.1\% sodium dodecyl sulphate [SDS], 1\% Nonidet P-40 [NP40] and $0.5 \mathrm{mmol} / \mathrm{L}$ EDTA; Elpis Biotech) for $30 \mathrm{~min}$. Protein concentrations were determined by a Bradford protein method. Equal protein quantities from each group were mixed with the SDSPAGE loading buffer (250 mmol/L Tris$\mathrm{HCl}$, pH 6.8, $0.5 \mathrm{~mol} / \mathrm{L} \mathrm{DTT,} \mathrm{10 \%} \mathrm{SDS,}$ $0.5 \%$ bromophenol blue, $50 \%$ glycerol), boiled for $10 \mathrm{~min}$, separated by SDSPAGE and transferred to polyvinylidene difluoride membranes (Roche Ltd). The membranes were probed with mouse antibodies against JNK, p-JNK, p38, p-p38, ERK, p-ERK, IkB- $\alpha$ (Cell Signaling Technology) and $\beta$-actin (Sigma) diluted 1:1,000 in 5\% Bovine serum albumin (BSA) and incubated with a goat anti-mouse IgG (Abbiotec) conjugated to horseradish peroxidase (HRP) secondary antibodies (Enzo Life Sciences). Immunoreactive bands were visualized by the enhanced chemiluminescence reaction.

\section{Determination of Serum Levels of Organ Damage Markers}

Serum levels of aspartate aminotransferase (AST), alanine aminotransferase (ALT) and lactate dehydrogenase (LDH) were measured by the Konkuk University Hospital Automatic Hematology Analyzer.

\section{Measurements of PMN Infiltration}

Lungs were perfused with $4 \%$ paraformaldehyde immediately after being excised from mice and kept at $4^{\circ} \mathrm{C}$ overnight. Fixed lung tissue was washed with distilled water for $2 \mathrm{~h}$ to remove Paraformaldehyde (PFA). Tissue processing was done using Auto Leica Tissue Processor 1020 (Leica Biosystems) that allowed for automatic control of tissue infiltration, dehydration and infiltration under vacuum. Lung tissue was perfused in formalin solution for $2 \mathrm{~h}$ and the procedure was repeated twice. Fixed lungs were then immersed into $70 \%, 80 \%, 90 \%$ and $100 \%$ ethanol, sequentially. After immersing in xylene, the tissues were embedded in paraffin and 7- $\mu \mathrm{m}$ sections were prepared. Slides were stored overnight at $65^{\circ} \mathrm{C}$ for deparaffinization. Tissues were hydrated by alcohol and rinsed with distilled water for $10 \mathrm{~min}$. Tissues were then stained with hematoxylin (Merck) and eosin (Merck). Images were captured with a digital camera (Nikon DS-Ri1) coupled to a Nikon Eclipse Ni microscope under 20× magnification.

\section{Tail Bleeding Assay}

Tail bleeding assay was performed as previously described (31). Mice were injected intraperitoneally with $50 \mathrm{mg} / \mathrm{kg}$ LPS or intravenously with 300 ug HMGB1. 
Annexin A5 $(500 \mu \mathrm{g} / \mathrm{mL})$ was intravenously administered as described. Twelve hours after the annexin A5 injection, each mouse was placed in prone position. Distal $1 \mathrm{~cm}$ of the tail tip was amputated with a scalpel and the tail was instantly immersed into a $50 \mathrm{~mL}$ tube containing PBS $\left(37^{\circ} \mathrm{C}\right)$. Each mouse was monitored until no more bleeding was observed for $1 \mathrm{~h}$, and they were euthanized by $\mathrm{CO}_{2}$ inhalation method. We estimated the blood volume that flowed out of the tails by calculating the mass of the $50 \mathrm{~mL}$ tube and measured the total bleeding time.

\section{Statistical Analysis}

All data were presented as the mean \pm SD of three independent experiments. Individual data points were compared by the Student $t$ test. Survival of mice was analyzed by the Kaplan-Meier method followed by the log-rank test. Analysis was performed using SPSS software (version 22.0). Differences between groups were considered significant at $P<0.05$.
All supplementary materials are available online at www.molmed.org.

\section{RESULTS}

\section{Annexin A5 Has a Therapeutic Effect in the Cecal Content Injection Model as well as in the LPS-Induced Endotoxemia Model}

To evaluate the therapeutic efficacy of annexin A5 in endotoxemia, we adopted the LPS-induced endotoxemia model as follows. We synthesized the recombinant human annexin A5 protein by transforming pET28a-annexin A5 plasmids into the Escherichia coli BL21 (DE3) strain. Having confirmed the expression of the protein by assessing its size and purity (Figure S1), we injected C57BL/6 mice intraperitoneally with lethal doses of LPS (50 mg/kg). Simultaneously, each mouse was intravenously injected with $500 \mu \mathrm{g}$ (in $100 \mu \mathrm{L}$ PBS) annexin A5 protein. As shown in Figure 1A, annexin A5 injection significantly increased survival rate of LPS-injected mice in the annexin A5 treatment group compared with the survival rate in the LPS-only challenged group. This shows that annexin A5 apparently has a therapeutic effect in the LPS-induced endotoxemia model.

To confirm the protective role of annexin A5 in a polymicrobial septic condition, a CCI-induced sepsis model was generated (30). C57BL/6 mice were intraperitoneally injected with a lethal dose (20 mg/mouse) of homogenized cecal contents. Each mouse was intravenously injected with $500 \mu \mathrm{g}$ (in $100 \mu \mathrm{L}$ PBS) of annexin A5 protein concurrently with CCI challenge. Annexin A5 treatment group exhibited significant protection against CCI-induced mortality compared with the CCI alone group (Figure 1B). We also confirmed the effectiveness of Annexin A5 treatment in the CCI model with the dose of $15 \mathrm{mg} /$ mouse, LD $_{50}$ (Figure S2).

This implies that the therapeutic effect

\section{A}

B

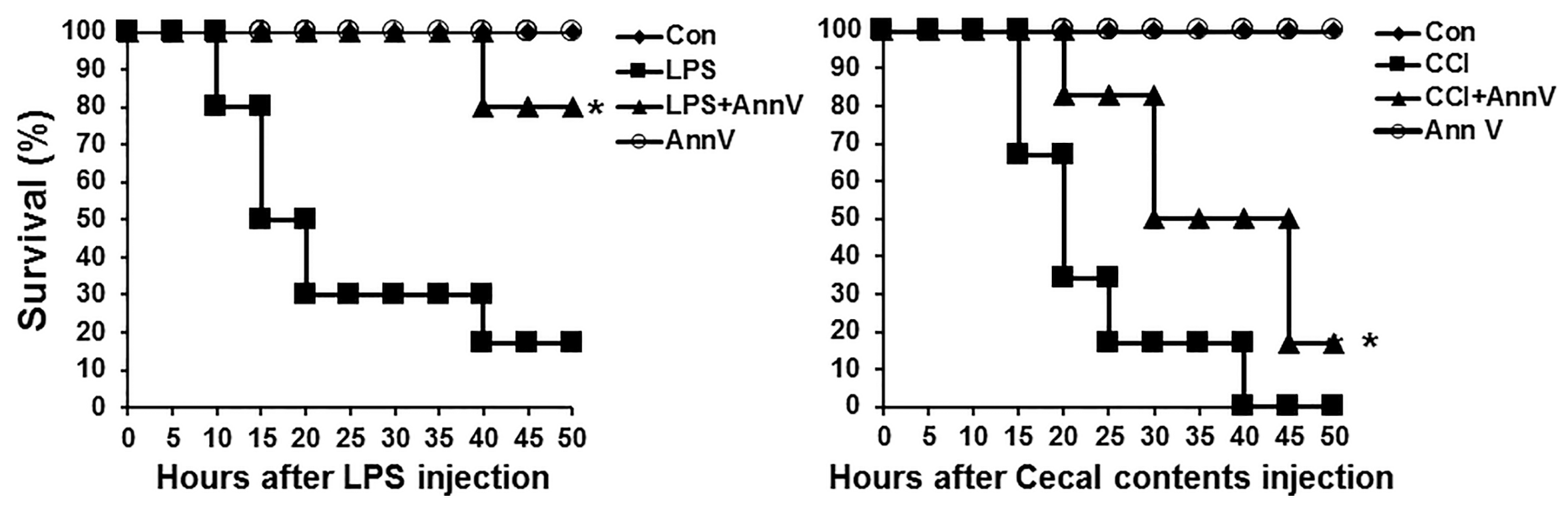

Figure 1. Annexin A5 treatment enhances survival in LPS-induced and cecal content injection-induced sepsis model. (A) endotoxemia model: C57BL/6 mice were intraperitoneally injected with lethal doses of LPS, $50 \mathrm{mg} / \mathrm{kg}$. Concurrently, each mouse was injected intravenously with $500 \mu \mathrm{g}$ annexin A5 (in $100 \mu \mathrm{LPBS}$ ) and monitored for $50 \mathrm{~h}$. * - indicates significant differences $(P<0.05)$ from data obtained during the LPS-only challenge. (B) cecal content injection model: C57BL/6 mice were intraperitoneally injected with 20 mg of cecal contents. Each mouse was intravenously injected with $500 \mu \mathrm{g}$ (in $100 \mu \mathrm{L}$ PBS) annexin A5 protein concurrently with $\mathrm{CCl}$ challenge and monitored for $50 \mathrm{~h} .{ }^{*}$ - Indicates significant differences $(P<0.05)$ from data obtained during the $\mathrm{CCl}$ challenge. In both $(A)$ and $(B)$, the line graph illustrates survival of C57BL/6 mice in different treatment groups over time. We monitored survived mice in each group for another three weeks, no unexpected death was observed. Each group consisted of 6 mice and the experiments were performed twice. Annexin A5 is abbreviated as "Ann V" and control group as "con." 
of annexin A5 persists in the polymicrobial septic condition as well as in endotoxemia.

\section{Annexin A5 Reduces LPS-Induced Dendritic Cell Activation and Maturation Levels by Inhibiting TLR4 Signaling Pathway in Endotoxemia}

Upon encountering the LPS originated from bacterial outer membranes, dendritic cells upregulate co-stimulatory molecules and proinflammatory cytokines $(32,33)$. To estimate the antiinflammatory effect of annexin A5 in the LPS-induced sepsis model, dendritic cells (DCs) were obtained from bone marrow of C57BL/ 6 mice and incubated with $50 \mathrm{ng} / \mathrm{mL}$ LPS in the presence of annexin A5 in different concentrations $(0,1,5$ and $10 \mu \mathrm{g} / \mathrm{mL})$. DC activation was characterized by measuring LPS-induced release of proinflammatory cytokines using ELISA. DC maturation markers CD40, CD80, and CD86 were then assessed using flow cytometry. In comparison to the LPS-only challenged group, annexin A5 protein treatment significantly decreased the production of proinflammatory cytokines IL6, TNF $\alpha$ and IL10 by DCs in a dose dependent manner (Figure 2A). Also, annexin A5 treatment decreased the expression of maturation surface markers CD40, CD80 and CD86 by DCs (Figure 2B). These results indicate that annexin A5 inhibits LPS-induced activation and maturation of DCs.

It has been suggested that annexin A5 protein can inhibit TLR4 signaling pathway by interrupting the interaction of LPS with the TLR4/MD2 complex (5). Thus, we reasoned that downregulation of cytokine production in DCs by annexin A5 (Figure 2A) may occur via inhibition of TLR4 signaling pathway. To confirm the relevance of TLR4 signaling for the attenuation of cytokine production by annexin A5, various signaling proteins in the TLR4 pathway were assessed by Western blot. DCs were cultured in the presence of annexin A5 protein $(20 \mu \mathrm{g} / \mathrm{mL})$ and LPS (50 $\mathrm{ng} / \mathrm{mL})$, and each signaling proteins were probed with designated antibodies. As shown in
Figure 2C, relatively strong phosphorylation of ERK, p38 and JNK were detected in DCs within 10 min of the LPS-only treatment. However, a concomitant administration of annexin A5 significantly decreased LPS-induced phosphorylation of these proteins in DCs (Figure 2C). Furthermore, annexin A5 treatment stabilized the expression of IkB- $\alpha$, indicating a suppression of NF-kB activation. These results support the notion that annexin A5 inhibits proinflammatory cytokine production in DCs during endotoxemia via inhibition of TLR4 pathway proteins.

\section{Annexin A5 Dampens Proinflammatory Cytokine Levels and Reduces the Magnitude of Organ Dysfunction and Tissue Damage in LPS-Induced Endotoxemia}

Dysregulation of proinflammatory cytokine production initiates a cytokine storm, which may lead to tissue damage and organ dysfunction $(8,34)$. To assess the effect of annexin A5 on LPS-induced proinflammatory cytokine production in vivo, dynamic changes in serum levels of proinflammatory cytokines IL6 and $\mathrm{TNF} \alpha$ were determined following annexin A5 administration to mice challenged with LPS. As shown in Figure 3A, injection of LPS led to a rise in serum IL6 and TNF $\alpha$ concentrations that peaked within $3 \mathrm{~h}$ after LPS injection and then gradually decreased. Notably, annexin A5 treatment caused a significant reduction of the levels of these cytokines in serum at each experimental time point. This result indicates that annexin A5 attenuates proinflammatory cytokine levels, and, therefore can potentially reduce progressive tissue damage during endotoxemia.

Since the cytokine storm can induce tissue damage and multi-organ failure (8), we examined the effect of annexin A5 treatment on LPS-induced organ damage by assessing serum concentrations of aspartate transaminase (AST), alanine transaminase (ALT) and blood urea nitrogen (BUN). Elevation of these parameters is known to positively correlate with impairment in liver and kidney functions. As shown in Figure 3B, serum levels of AST, ALT and BUN were substantially increased during the $18-\mathrm{h}$ period after LPS injection. However, their concentrations at similar time periods were significantly reduced when annexin A5 was co-administered with LPS. These results suggest that annexin A5 treatment may reduce organ damage during LPS-induced endotoxemia.

Cellular infiltration of polymorphonuclear leukocytes (PMN) causes direct tissue damage by releasing lysosomal enzymes and superoxide-derived free radicals (7). To assess the potential reduction of tissue damage by annexin A5, we examined PMN infiltration in the lung following LPS challenge. Massive lung PMN infiltration was observed following LPS injections, while co-administration of annexin A5 and LPS significantly reduced the amount of PMN infiltration (Figure 3C). This result implies that annexin A5 protein has a protective effect against tissue damage caused by LPS.

\section{Annexin A5 Dampens HMGB 1- Mediated Proinflammatory Response by Inhibiting TLR4 Signaling in Dendritic Cells}

It has been reported that inhibition of LPS-TLR4 signaling is ineffective in protecting LPS-induced organ damage in mice once the amount of cytokines in serum reach toxic level, which occurs within 1-2 h of LPS administration $(17,19,35)$. Thus, we hypothesized that if annexin A5's antiinflammatory response occurs exclusively via interrupting LPS and TLR4 interaction, a delay in treatment will abrogate its protective effect in the endotoxemia model. C57BL/ 6 mice were injected intraperitoneally with $50 \mathrm{mg} / \mathrm{kg}$ LPS. Three hours after LPS challenge, each mouse was intravenously

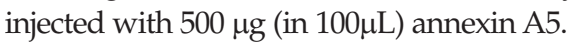
Surprisingly, a 3-h delay of annexin A5 injection still significantly increased the survival of mice challenged with LPS compared with those without annexin A5 treatment (Figure 4A). This protective effect in delayed administration implies that annexin A5 may be able to inhibit 


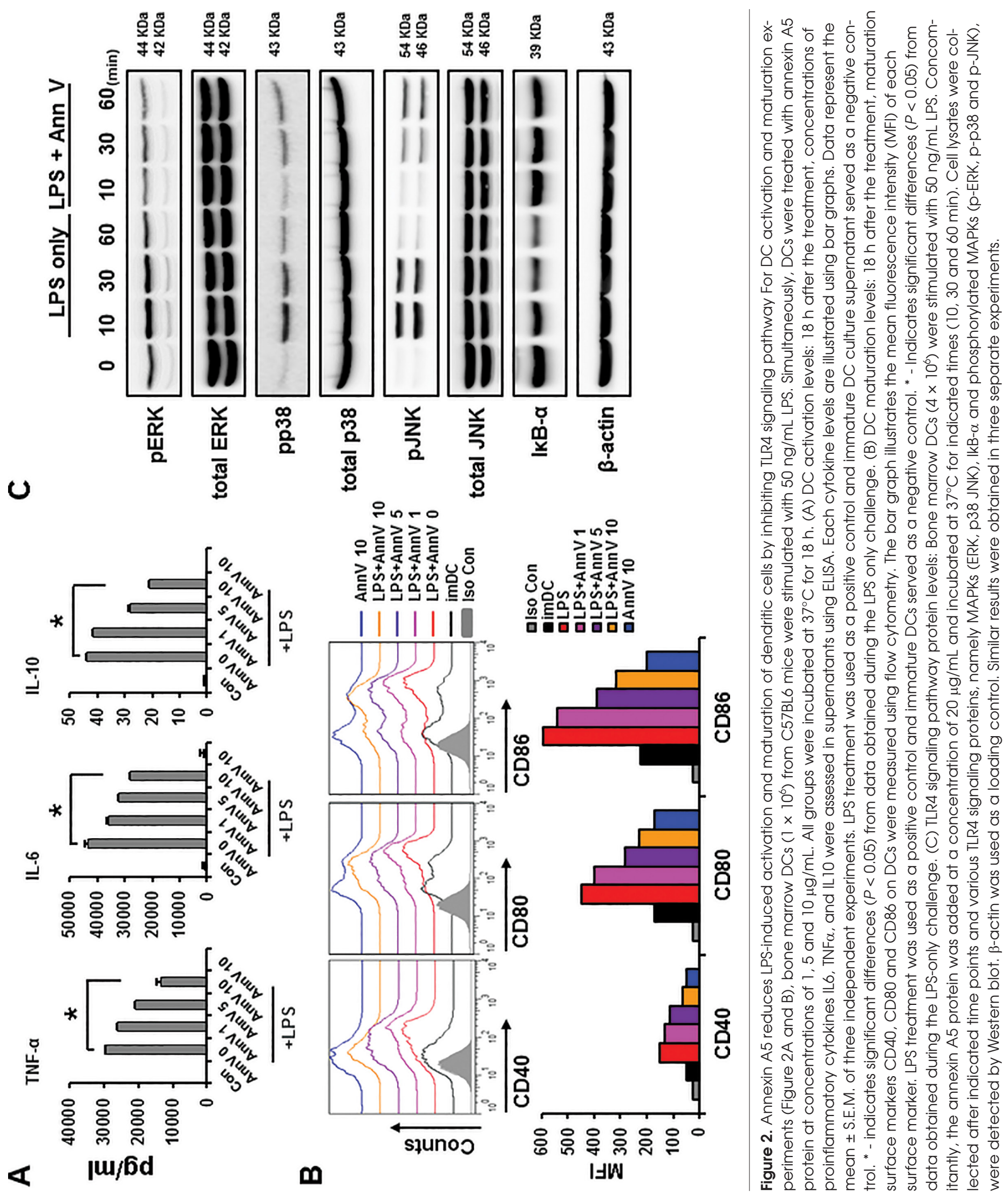




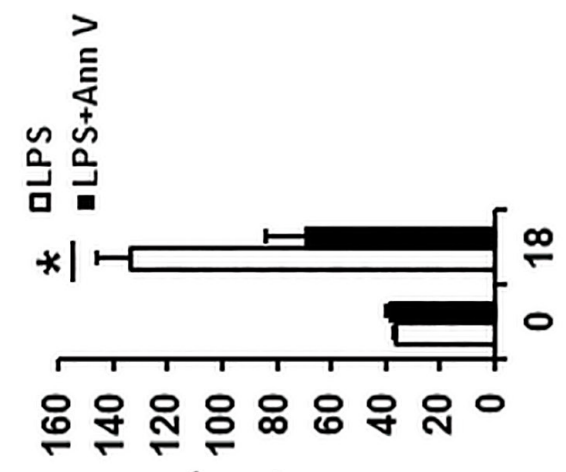

(าini) Nกg
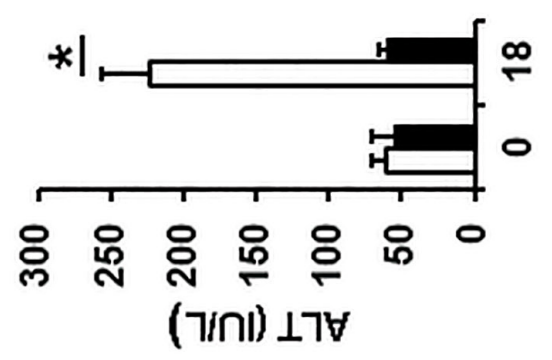

$m$

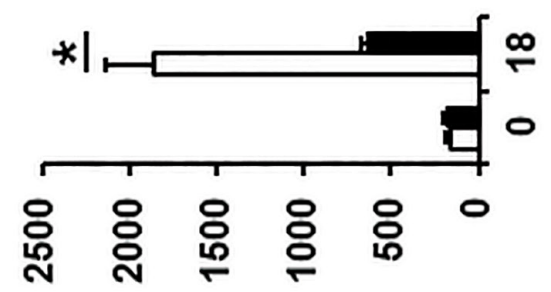

(าIחI) $\perp S \forall$

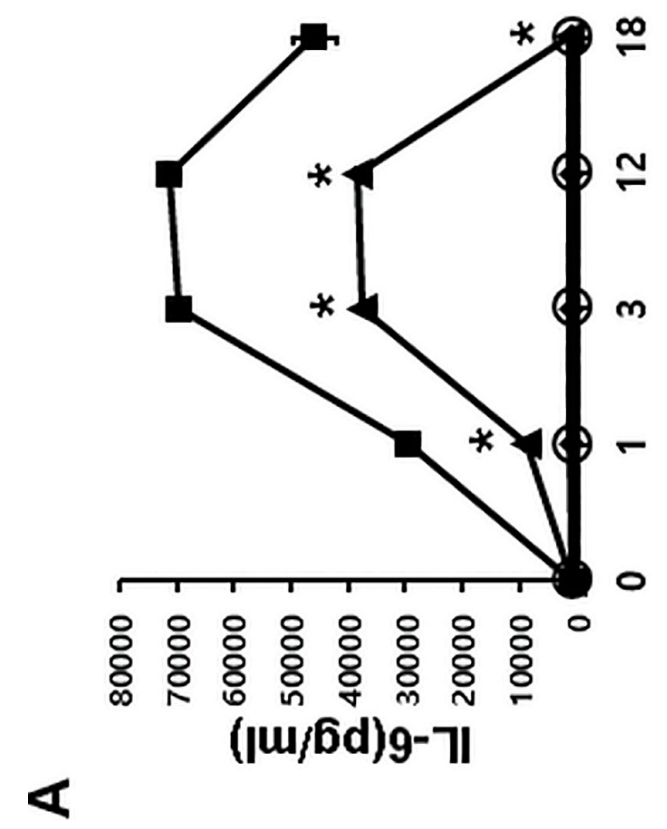

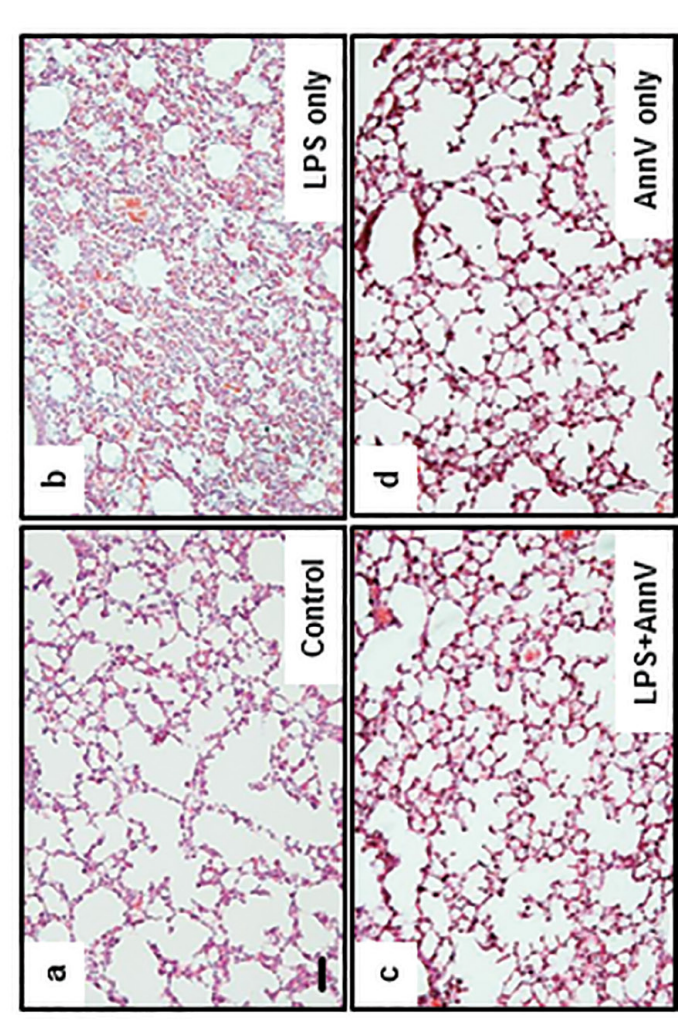

U

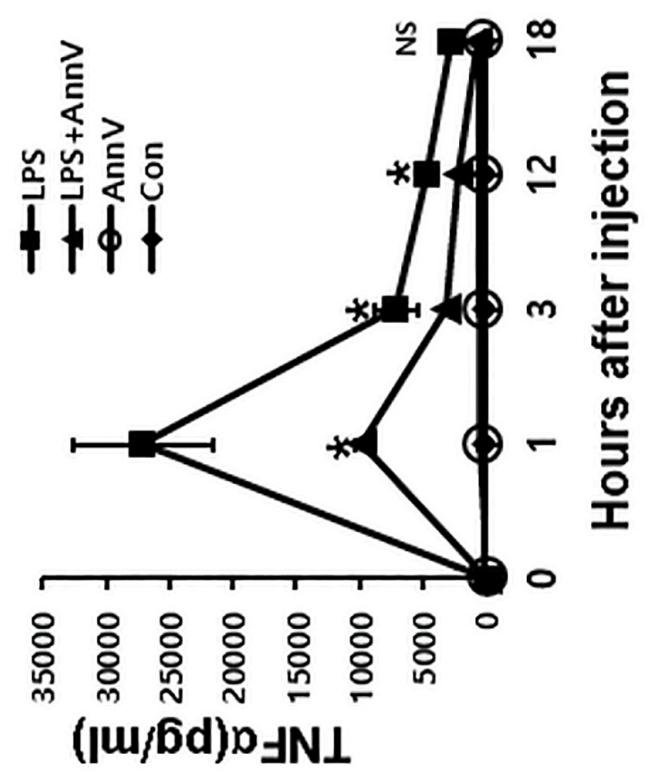

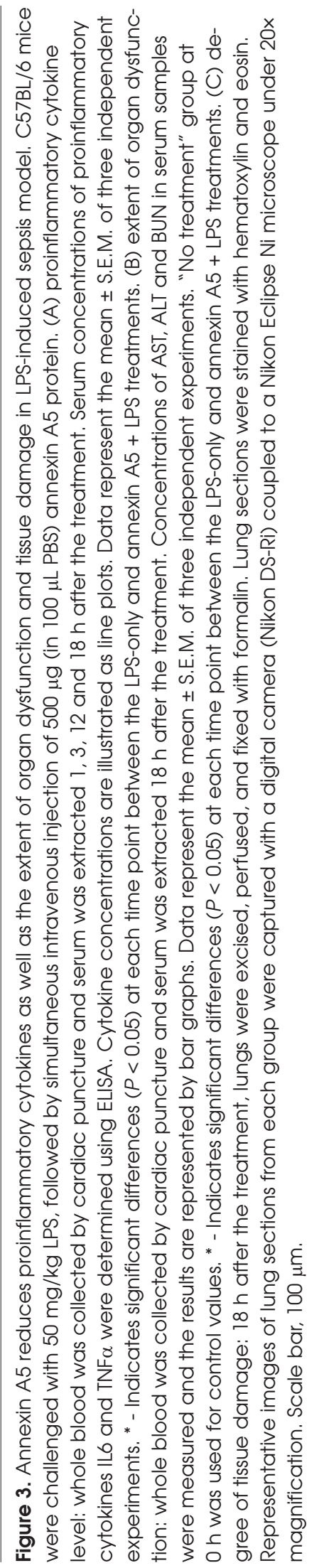



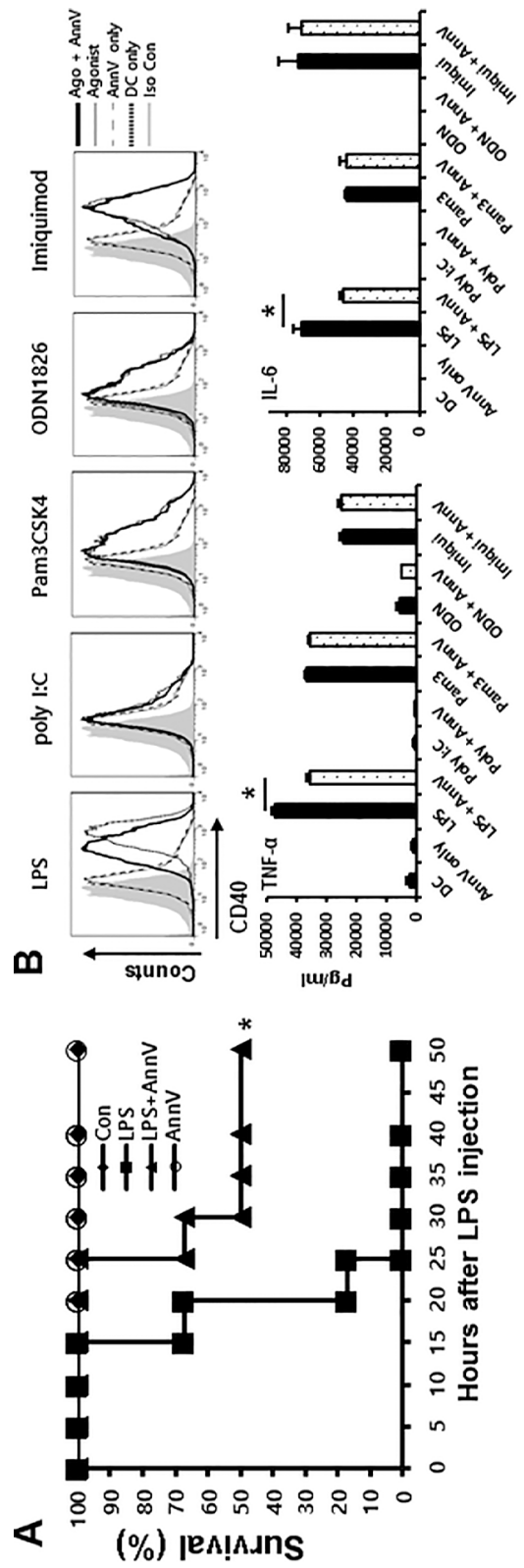

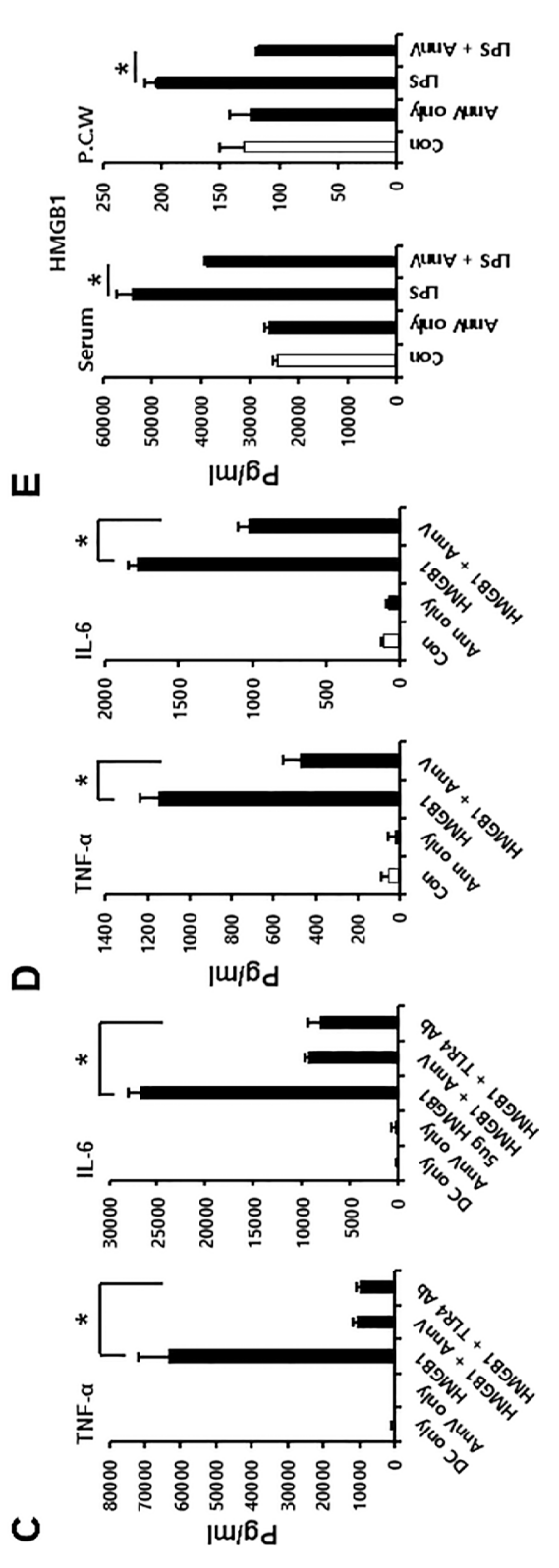

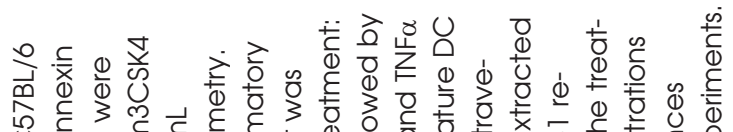

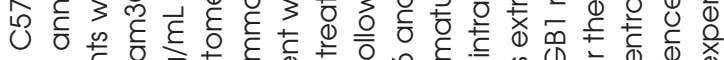

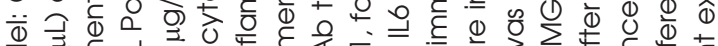

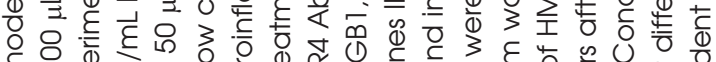

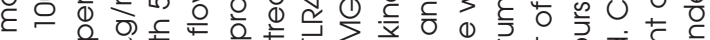

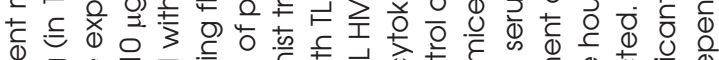
ह O

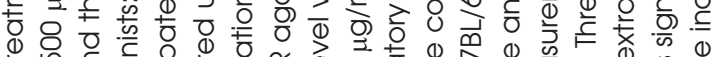
O f o

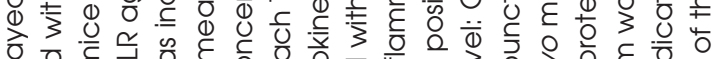

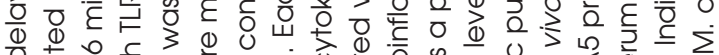

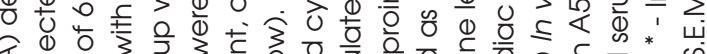

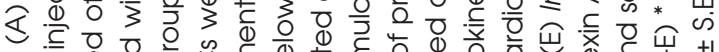

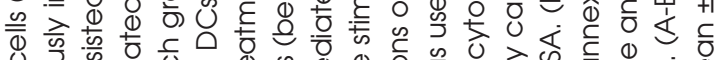

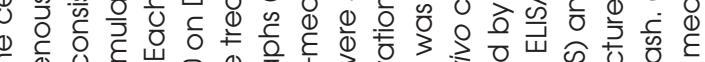

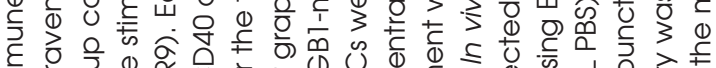

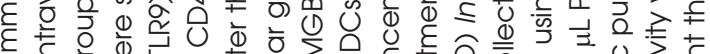

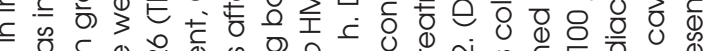

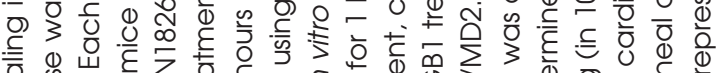

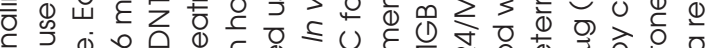

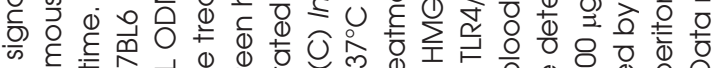

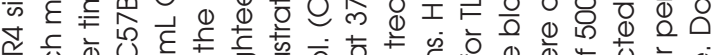

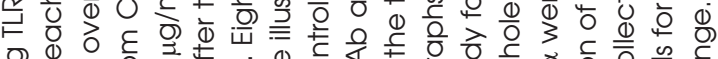

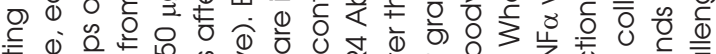

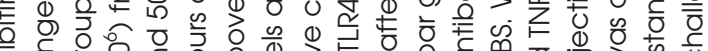

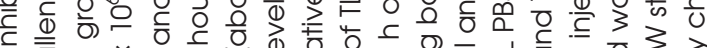

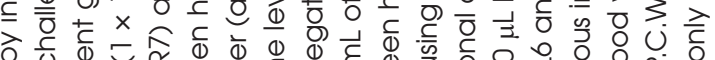
ه क

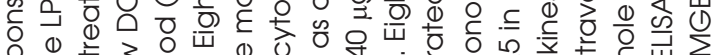

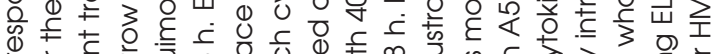

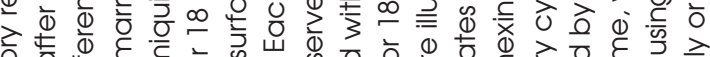

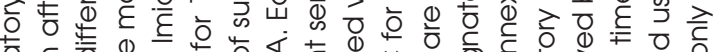

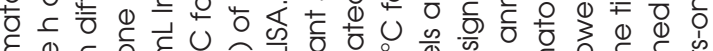

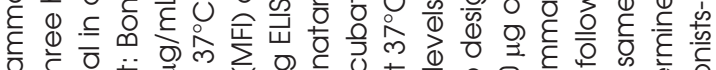
을 $\overline{0}$

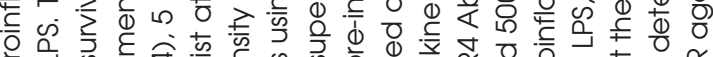

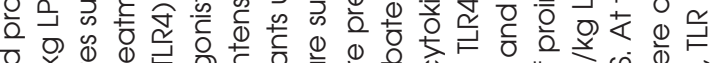

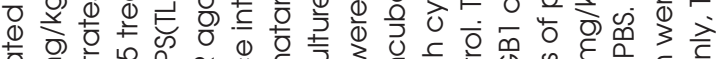
흠

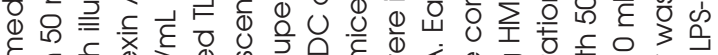

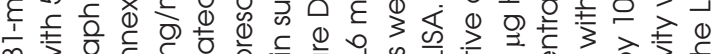

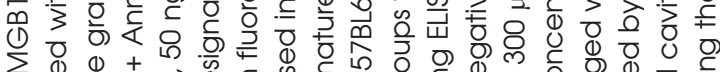

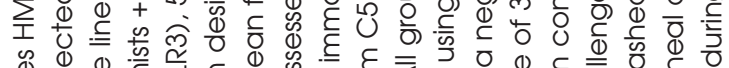

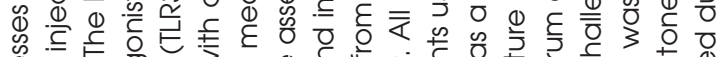

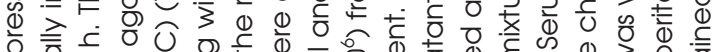

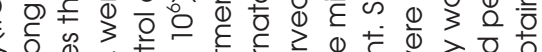
के

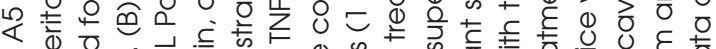

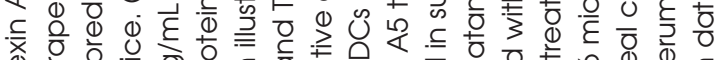

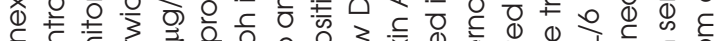

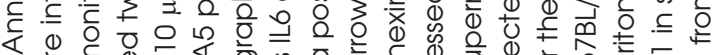

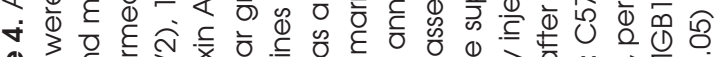

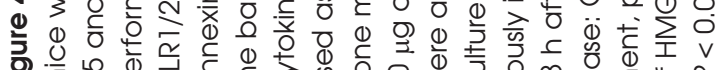


other signaling pathway or to interrupt other substances interacting TLR4.

To verify whether annexin A5 can interact with other TLR signaling processes, we stimulated dendritic cells with several TLR ligands, including $10 \mathrm{ug} / \mathrm{mL}$ Pam3CSK4 (TLR1/2), $10 \mathrm{ug} / \mathrm{mL}$ Poly(I:C) (TLR3), $50 \mathrm{ng} / \mathrm{mL}$ LPS (TLR4), $5 \mathrm{ug} / \mathrm{mL}$ Imiquimod (TLR7) and $50 \mathrm{ug} / \mathrm{mL}$ ODN1826 (TLR9). Each designated groups were incubated with Annexin A5 (50ug/mL). We then characterized CD40 as a DC maturation marker by FACS analysis, and determined the levels of IL6 and TNFo in supernatant as DC activation markers using ELISA. As shown in Figure 4B, annexin A5 did not alter the expression of CD40 or the secretion of IL6 and TNF $\alpha$ elicited by the presence of TLR agonists with the exception of LPS, a TLR4 agonist. These results imply that annexin A5 attenuates proinflammatory cytokine exclusively via inhibition of TLR4 signaling.

Next, we supposed that annexin A5 may interrupt the interaction of TLR4 with substance other than LPS. In search of TLR4 interacting substances other than LPS, which annexin A5 may interrupt, we looked in HMGB1, a late acting mediator, as a strong potential candidate. The critical role of TLR4 signaling in HMGB1-mediated cytokine release has been strongly supported by TLR4 knockout experiments in immune cells $(13,14,36)$. In addition, HMGB1 is known to produce proinflammatory cytokines via the identical receptor complex (TLR4/MD2) as LPS $(13,14,37)$. Thus, we hypothesized that annexin A5 may inhibit HMGB1-mediated proinflammatory cytokine production by interrupting HMGB1 and TLR4 interaction. To test our hypothesis, we first confirmed the TLR4 dependency of HMGB1-mediated cytokine production in dendritic cell. DCs or TLR4 Ab $(40 \mu \mathrm{g} / \mathrm{mL})$ treated DCs were incubated with $5 \mu \mathrm{g} / \mathrm{mL}$ HMGB1 in the presence of $50 \mu \mathrm{g} / \mathrm{mL}$ annexin A5. We then characterized DC activation by measuring HMGB1-induced release of proinflammatory cytokines using ELISA. As shown in Figure 4C, TLR4 antibody abrogated HMGB1-mediated IL6 and TNF $\alpha$ secretions, which confirms that dendritic cells produce HMGB1-mediated cytokine via TLR4 signaling. In addition, annexin A5 protein treatment significantly decreased the production of IL6 and TNF $\alpha$ in HMGB1 challenged DCs compared with those that did not receive annexin A5 treatment (Figure 4C). HMGB1-mediated DC maturation levels were also decreased by annexin A5 treatment (Figure S3). We subsequently confirmed the antiinflammatory role of annexin A5 in mice challenged with HMGB1. While injection of HMGB1 led to increase in serum level of IL6 and $\mathrm{TNF} \alpha$, the levels of these cytokines were notably reduced in annexin A5 treatment group (Figure 4D). Both in vitro and in vivo demonstrations imply that annexin A5 attenuates HMGB1-mediated proinflammatory cytokine levels partly by interrupting HMGB1-TLR4 signaling.

Wang et al. discovered that serum HMGB1 levels are elevated in endotoxemia models and in patients with sepsis (6). To assess the effect of annexin A5 on LPS-induced HMGB1 release, in vivo, serum HMGB1 level was determined following annexin A5 administration to mice challenged with LPS. C57BL/ 6 mice were injected intraperitoneally with $50 \mathrm{mg} / \mathrm{kg}$ LPS, followed by intravenous injection of $500 \mu \mathrm{g}$ (in $100 \mu \mathrm{L}$ ) annexin A5 protein. Three hours after the treatment, concentrations of HMGB1 in serum and peritoneal cavity wash were determined using ELISA. As shown in Figure 4E, annexin A5 treatment significantly reduced the serum concentration of HMGB1. This result implies that annexin A5 may reduce HMGB1 release during LPS-induced endotoxemia.

\section{Annexin A5 Reduces LPS- and HMGB 1-Mediated Pro-Coagulation in Septic Condition}

Both LPS $(38,39)$ and HMGB1

$(11,12,20)$ have been suggested to induce coagulation, and each substance is considered as a single factor for aggravating tissue impairment in septic patients
$(7,20,40)$. Since annexin A5 is known to exert antithrombotic action by binding exposed phosphatidylserine on the platelet surface $(5,24-27)$, we determined to examine whether annexin A5 maintains its anticoagulant property in septic condition. First, we verified whether LPS challenge elevates coagulation status and induces annexin A5 binding (Figure S4). To investigate whether annexin A5 mitigates coagulation during sepsis, a tail bleeding assay was performed. Tail bleeding assay is widely used to evaluate effects of antiplatelet drugs in murine models, and assesses bleeding time and volume of blood drained from a tail following amputation of its distal section. (31). As shown in Figure 5A, co-administration of annexin A5 and LPS led to an increase in bleeding time and bleeding volume compared with the values of these parameters in mice that did not receive annexin A5 treatment. This observation suggests that annexin A5 is able to alleviate LPSmediated coagulation in septic condition.

Suppression of inflammation may reduce tissue factor production during sepsis, which also improves a patient's coagulation status (41). Activated protein $C$ is a well-known innate anti-coagulant, and decreased synthesis of protein $C$ is one of the characteristics of severe sepsis (42). We observed that annexin A5 treatment did not alter plasma level of tissue factor and protein $C$ during the same experimental conditions in the tail bleeding assay described above (Figure S5).

To further examine whether the annexin A5 maintains its anticoagulant property in a late septic condition where serum HMGB1 has been elevated, we performed an additional tail bleeding assay in the delayed treatment model and the HMGB1-challenged model. Delay in treatment of annexin A5 did not abrogate the anticoagulant property of annexinA5 in endotoxemia model (Figure 5B). Also, we found that HMGB1 itself promotes coagulation, which is inhibited by the administration of annexinA5 (Figure 5C). These observations imply that annexinA5 may play a role in inhibiting the HMGB1-mediated coagulation 
A

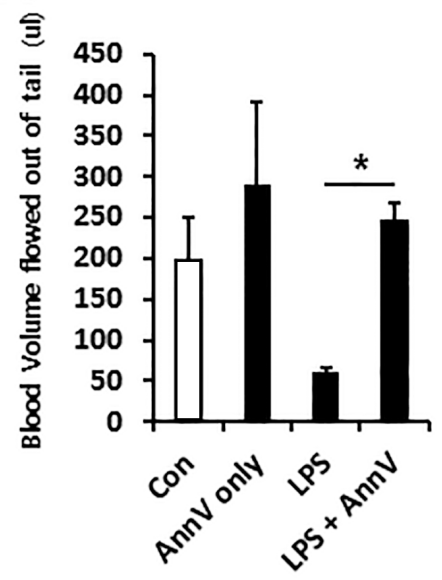

C

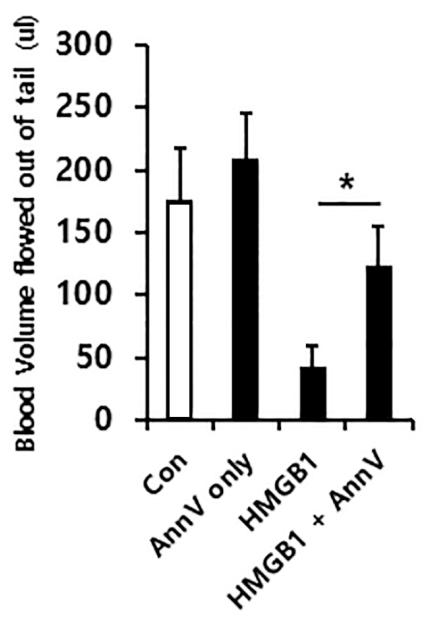

B

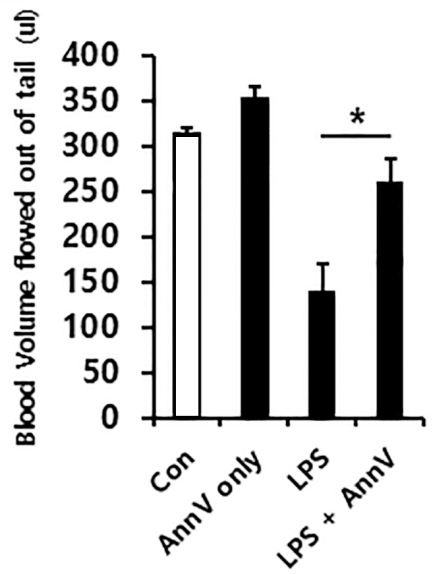

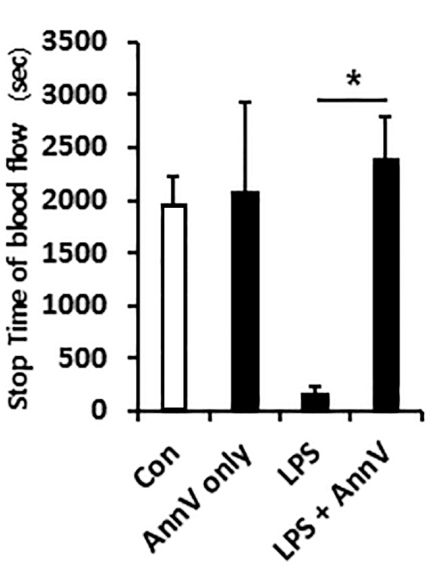
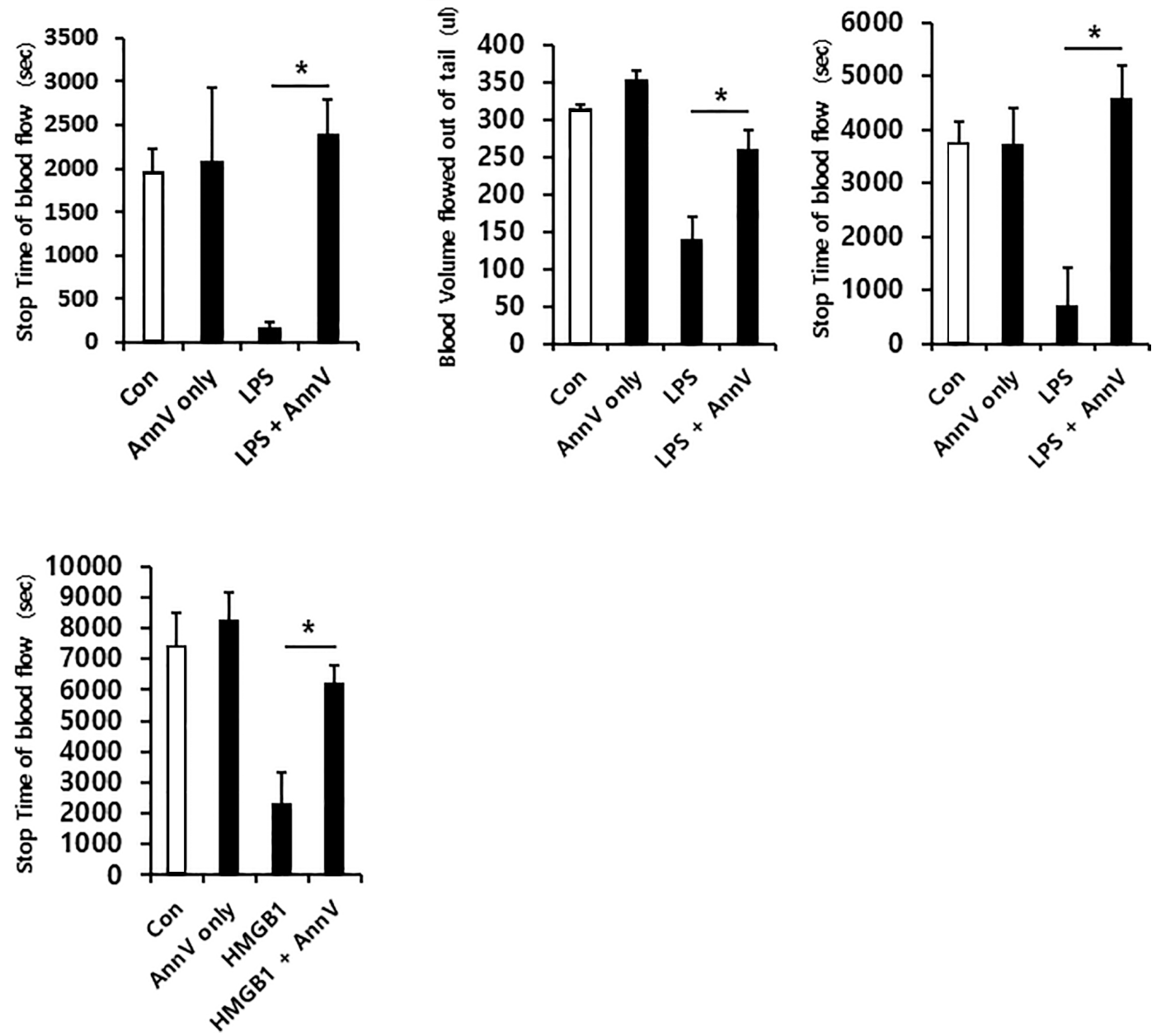

Figure 5. Annexin A5 reduces LPS- and HMGB1-mediated pro-coagulation in septic conditions. (A) LPS-challenged group: C57BL/6 mice were intraperitoneally injected with $50 \mathrm{mg} / \mathrm{kg}$ LPS. Concurrently, each mouse was intravenously injected with $500 \mu \mathrm{g}$ (in $100 \mu \mathrm{L}$ PBS) annexin A5 protein. Twelve hours after the treatment, the distal $1 \mathrm{~cm}$-long portion of the tail tip was amputated. (B) delayed treatment group: C57BL/6 mice were intraperitoneally injected with $50 \mathrm{mg} / \mathrm{kg}$. Three hours after the LPS challenge, each mouse was intravenously injected with $500 \mu \mathrm{g}$ (in $100 \mu \mathrm{L}$ PBS) annexin A5. Twelve hours after treatment, the distal $1 \mathrm{~cm}$-long portion of the tail tip was amputated. (C) HMGB1-challenged group: C57BL/6 mice were intravenously injected with the mixture of $300 \mu \mathrm{H} H \mathrm{HGBl}$ and $500 \mu \mathrm{g}$ annexin A5 in $100 \mathrm{uL}$ PBS. Three hours after the treatment, the distal $1 \mathrm{~cm}$-long portion of the tail tip was amputated. (A-C) Volume of blood flowed out of tail (in $\mu \mathrm{L}$ ) and the time of cessation of blood flow (in seconds) were monitored and illustrated on the bar graph. Each group consisted of 3 mice and the experiments were performed twice. * - Indicates significant differences $(P<0.05)$ from data obtained during the LPS- or HMGB1-only challenge.

process, suggesting the potential use of annexin A5 as anticoagulant therapy against various septic conditions.

\section{DISCUSSION}

In the present study, we explored the regulation of LPS- and HMGB1-mediated inflammatory response in immune cells by annexin $\mathrm{A} 5$ and determined the therapeutic role of annexin A5 as an anticoagulant in the sepsis model. In the clinical setting, the time gap between diagnosis of sepsis and the onset of infection is inevitable (43). The present study highlights the clinical relevance of annexin A5 based on the double therapeutic potentials, including (a) inhibition of inflammation derived by both initial and late mediators, LPS and HMGB1, respectively, and (b) persistence of anti-coagulant property in LPS- and HMGB1- induced sepsis model.
The therapeutic potential of annexin A5 as an endotoxin inhibitor in sepsis has been established in recent reports. Rand et al. first found that annexin A5 reduces LPS-induced TNF- $\alpha$ production (28). Arnold et al. also showed that annexin A5 decreases myocardial TNF- $\alpha$ expression by inhibition of LPS binding TLR4/MD2 complex, improving cardiac function and survival during endotoxemia (5). In accordance with these observations, we 
confirmed that annexin A5 reduces the production of LPS-induced proinflammatory cytokines IL6 and TNF $\alpha$ via blocking of TLR4 signaling in dendritic cells (Figure 2). We also found that annexin A5 treatment improves tissue damage and liver function in sepsis, consistent to the reduction of proinflammatory cytokine production (Figure 3). Blockage of LPS-TLR4 signaling, however, cannot fully explain the protective effect of annexin A5 against endotoxin lethality in delayed treatment model (Figure 4A). For example, therapeutic efficacy of another potential candidate to treat sepsis condition, the platelet-activating factor, was greatly diminished when the treatment was delayed by $3 \mathrm{~h}$ (44).

We postulated that the protective effect of annexin A5 in delayed treatment model (Figure 4A) is derived by blocking HMGB1, a late-acting mediator of systemic inflammation. It is well established that HMGB1 plays a role as a DAMP via TLR4 signaling, which promotes late proinflammatory cytokine production $(6,9,13,14)$. Delayed administration of neutralizing anti-HMGB1 antibodies still protect against sepsis lethality $(6,9)$. Antagonizing HMGB1 downregulated HMGB1-indcued TNF $\alpha$ and IL-6 release $(6,9,13,14)$ and reduced liver damage (13). In accordance with these observations, we demonstrated both in vitro and in vivo that HMGB1 elevates proinflammatory cytokine TNF $\alpha$ and IL-6, and annexin A5 dampen the secretion of these cytokines (Figure 4C, D). Since inhibition of LPS binding TLR4/MD2 complex is the key mechanism of how annexin A5 suppresses LPS-mediated cytokine production, we postulated that annexin A5 may be able to inhibit HMGB1 binding to TLR4/MD2 complex $(13,14,37)$. Recently, Yang et al. reported that HMGB1 binds to MD2 and showed that MD2-deficient macrophage fails to produce cytokine (13). They further identified that HMGB1 typically binds to MD2 domain within the TLR4 receptor when it is in disulfide form (13). Annexin A5 appears to compete with disulfide from of HMGB1 for binding to MD2/TLR4, thereby inducing antiinflammatory response. However, whether annexin A5 inhibits HMGB1 binding to MD2 via competitive or non-competitive manner is yet to be solved. Also, since HMGB1 is known to interact with other receptors, including TLR2 and RANGE, we should consider the possibility of the interaction between annexin $\mathrm{A} 5$ and these receptors (10). According to Figure 4B, annexin A5 and TLR1/2 complex appears to have no interaction; since annexin A5 was not able to reverse Pam3CSK4 (TLR1/2)mediated dendritic cell activation. Furthermore, annexin A5 is known to compete with RAGE for phosphatidylserine binding, which limits the possibility of direct binding (45). Our additional results partly support these findings in that TLR4/MD2 antibody abrogated HMGB1-mediated cytokine production in dendritic cells, the results of which were also reproduced by annexin A5 treatment (Figure 4C). In addition to this HMGB1 antagonizing effect, we demonstrated in vivo that annexin A5 treatment reduced the serum HMGB1 level in LPS challenged mice (Figure 4E). The active release of HMGB1 by immune cells is partially dependent on LPS-mediated TLR4 signaling $(10,46)$. We speculate that annexin A5 potentially inhibits the release of HMGB1 by inhibiting both LPSand HMGB1-mediated TLR4 signaling. Together, our results demonstrate that persistent therapeutic effect of annexin A5 in delayed treatment model are derived from annexin A5's double protecting capacity against LPS- and HMGB1- mediated immune responses.

In the study we also identified that the anticoagulant property of annexin A5 plays an important role in prolonging the survival under LPS- and HMGB1induced sepsis. By using a tail bleeding assay, we confirmed the persistence of annexin A5's anticoagulant capacity in various septic conditions including LPS and HMGB1 exposure (Figure 5). We postulate that annexin A5 exerts its anticoagulant property shown in the sepsis models by directly shielding the phosphatidylserine exposed on the platelet surface, thereby prohibiting platelet plug formation $(5,24-27)$. Anticoagulation, however, may also be indirectly derived as a secondary consequence of reduced inflammation upon annexin A5 treatment. Thus, we confirmed that some factors in coagulation cascade, including tissue factor and protein $\mathrm{C}$, are not altered during annexin A5 treatment in sepsis models (Figure S5).

The persistent anticoagulant effect of annexin A5 in septic conditions has interesting clinical implications. In particular, the systemic activation of blood coagulation during sepsis generates and deposits fibrin leading to microvascular thrombi accumulation in various organs, a process that contributes to eventual organ dysfunction $(22,47)$. To prevent patients from developing the coagulopathy, the adequate use of anticoagulants is critical in sepsis treatment. Strong anticoagulants, however, are often contraindicated for patients with a septic condition $(48,49)$. Also, the failure of clinical trials associated with anticoagulants in sepsis treatment is largely attributed to severe bleeding (49). Xigris (a recombinant form of the human activated protein $C$ marketed by Eli Lilly and Company) was once approved by the U.S. Food and Drug Administration as sepsis-specific therapy, yet was withdrawn later due to its severe bleeding risk $(5,48,50)$. In light of the existing need for relatively milder anticoagulants, the fact that annexin A5 does not exert a potent antithrombolytic effect makes this protein particularly promising for sepsis treatment $(5,49,51)$.

There are competing theories of explaining late deaths in sepsis: one is due to intractable inflammation-induced organ injury, and the other is owing to persistent immunosuppression (52). Overall, our group demonstrated the effect of annexin A5 based on the former point of view. However, annexin A5 appears to attenuate LPS-induced lymphopenia (Figure S6), implying a beneficial role that can be interpreted based on the latter aspect. Since TLR4 inhibition itself is known to have no effect in decreasing 
LPS-induced lymphopenia (53), the exact mechanism of annexin A5 attenuating lymphocyte clearance in sepsis remains for future study.

\section{CONCLUSION}

In summary, our present study demonstrated that annexinA5 inhibits TLR4-mediated immune response by blocking the interaction of both LPS and HMGB1 with TLR4/MD2. We showed that annexin A5 exerts a doubleprotecting effect on proinflammation, as well as persistency of its anticoagulation capacity during various septic conditions. Together, these findings suggest annexin $\mathrm{A} 5$ as a promising alternative therapeutic approach for treatment of patients with sepsis.

\section{ACKNOWLEDGMENTS}

This study was supported by the National Research Foundation of Korea (NRF) grant funded by the Korea government (NRF-2016R1A5A2012284, NRF-2015R1A2A1A13001713, NRF2013R1A1A2059752) and supported by Basic Research Laboratory Program through the National Research Foundation of Korea (NRF) funded by the Ministry of Science, ICT \& Future Planning (NRF-2013R1A4A1069575). This study was also supported by a grant of Korea Health Technology R\&D project through the Korea Health Industry Development Institute (KHIDI), funded by the Ministry of Health \& Welfare, Republic of Korea (grant number : HI15C2524)

\section{DISCLOSURE}

The authors declare that they have no competing interests as defined by Molecular Medicine, or other interests that might be perceived to influence the results and discussion reported in this paper.

\section{REFERENCES}

1. Angus DC, van der Poll T. (2013) Severe sepsis and septic shock. The New England journal of medicine 369:840-51.

2. Martin GS. (2012) Sepsis, severe sepsis and septic shock: changes in incidence, pathogens and outcomes. Expert review of anti-infective therapy 10:701-6.
3. Scumpia PO, et al. (2005) CD11c+ dendritic cells are required for survival in murine polymicrobial sepsis. J. Immunol. 175:3282-6.

4. Mogensen TH. (2009) Pathogen recognition and inflammatory signaling in innate immune defenses. Clin Microbiol Rev 22:240-73, Table of Contents.

5. Arnold P, et al. (2014) Recombinant human annexin A5 inhibits proinflammatory response and improves cardiac function and survival in mice with endotoxemia. Crit. Care Med. 42: e32-41.

6. Wang H, et al. (1999) HMG-1 as a late mediator of endotoxin lethality in mice. Science 285:24851.

7. Cohen J. (2002) The immunopathogenesis of sepsis. Nature 420:885-91.

8. Wang H, Ma S. (2008) The cytokine storm and factors determining the sequence and severity of organ dysfunction in multiple organ dysfunction syndrome. The American journal of emergency medicine 26:711-15.

9. Tracey KJ, et al. (1987) Anti-cachectin/TNF monoclonal antibodies prevent septic shock during lethal bacteraemia. Nature 330:662-4.

10. Lotze MT, Tracey KJ. (2005) High-mobility group box 1 protein (HMGB1): nuclear weapon in the immune arsenal. Nat Rev Immunol 5:331-42.

11. Vogel S, et al. (2015) Platelet-derived HMGB1 is a critical mediator of thrombosis. J. Clin. Invest. 125:4638-54.

12. Yang $X$, et al. (2015) HMGB1: a novel protein that induced platelets active and aggregation via Tolllike receptor-4, NF-kappaB and cGMP dependent mechanisms. Diagn Pathol 10:134.

13. Yang H, et al. (2015) MD-2 is required for disulfide HMGB1-dependent TLR4 signaling. J. Exp. Med. 212:5-14.

14. Yang H, et al. (2010) A critical cysteine is required for HMGB1 binding to Toll-like receptor 4 and activation of macrophage cytokine release. Proc. Natl. Acad. Sci. U. S. A. 107:11942-7.

15. Park JS, et al. (2006) High mobility group box 1 protein interacts with multiple Toll-like receptors. Am. J. Physiol. Cell Physiol 290: C917-24.

16. Yang H, et al. (2004) Reversing established sepsis with antagonists of endogenous high-mobility group box 1. Proc. Natl. Acad. Sci. U. S. A. 101:296-301.

17. Wang H, Yang H, Czura CJ, Sama AE, Tracey KJ. (2001) HMGB1 as a late mediator of lethal systemic inflammation. Am. J. Respir. Crit. Care Med. 164:1768-73.

18. Li L, et al. (2015) Heparin inhibits the inflammatory response induced by LPS and HMGB1 by blocking the binding of HMGB1 to the surface of macrophages. Cytokine 72:36-42.

19. Cheng Y, et al. (2015) Escin Increases the Survival Rate of LPS-Induced Septic Mice Through Inhibition of HMGB1 Release from Macrophages. Cell Physiol Biochem 36:1577-86.

20. Ito T, et al. (2007) High-mobility group box 1 protein promotes development of microvascular thrombosis in rats. J Thromb Haemost 5:109-116.
21. Esmon CT. (2005) The interactions between inflammation and coagulation. Br J Haematol 131:417-30.

22. Vincent JL, De Backer D. (2005) Does disseminated intravascular coagulation lead to multiple organ failure? Critical care clinics 21:469-77.

23. Hatada T, et al. (2005) Plasma concentrations and importance of High Mobility Group Box protein in the prognosis of organ failure in patients with disseminated intravascular coagulation. Thromb Haemost 94:975-9.

24. Tait JF, Gibson D, Fujikawa K. (1989) Phospholipid binding properties of human placental anticoagulant protein-I, a member of the lipocortin family. The Journal of biological chemistry 264:7944-9.

25. Galan AM, et al. (2006) Antithrombotic action of annexin $\mathrm{V}$ proved as efficient as direct inhibition of tissue factor or thrombin. European journal of clinical investigation 36:633-39.

26. van Heerde WL, Poort S, van 't Veer C, Reutelingsperger CP, de Groot PG. (1994) Binding of recombinant annexin $\mathrm{V}$ to endothelial cells: effect of annexin $\mathrm{V}$ binding on endothelial-cellmediated thrombin formation. The Biochemical journal 302 ( Pt 1): 305-12.

27. Reutelingsperger CP, van Heerde WL. (1997) Annexin V, the regulator of phosphatidylserinecatalyzed inflammation and coagulation during apoptosis. Cellular and molecular life sciences : CMLS 53:527-32.

28. Rand JH, et al. (2012) Annexin A5 binds to lipopolysaccharide and reduces its endotoxin activity. MBio 3.

29. Nemzek JA, Xiao HY, Minard AE, Bolgos GL, Remick DG. (2004) Humane endpoints in shock research. Shock 21:17-25.

30. Yim HS, et al. (2013) Effect of 1-methyl-Dtryptophan and adoptive transfer of dendritic cells on polymicrobial sepsis induced by cecal content injection. Microbiol Immunol 57:633-39.

31. Liu Y, Jennings NL, Dart AM, Du XJ. (2012) Standardizing a simpler, more sensitive and accurate tail bleeding assay in mice. World J. Exp. Med. 2:30-6.

32. Abdi K, Singh NJ, Matzinger P. (2012) Lipopolysaccharide-activated dendritic cells: "exhausted" or alert and waiting? Journal of immunology 188:5981-9.

33. Verhasselt V, et al. (1997) Bacterial lipopolysaccharide stimulates the production of cytokines and the expression of costimulatory molecules by human peripheral blood dendritic cells: evidence for a soluble CD14-dependent pathway. Journal of immunology 158:2919-25.

34. Stich N, Waclavicek M, Model N, Eibl MM. (2010) Staphylococcal superantigen (TSST-1) mutant analysis reveals that $t$ cell activation is required for biological effects in the rabbit including the cytokine storm. Toxins 2:2272-88.

35. Andersson U, et al. (2000) High mobility group 1 protein (HMG-1) stimulates proinflammatory cytokine synthesis in human monocytes. J. Exp. Med. 192:565-70. 
36. Andersson U, Tracey KJ. (2011) HMGB1 is a therapeutic target for sterile inflammation and infection. Annu Rev Immunol 29:139-62.

37. Yang H, Wang H, Chavan SS, Andersson U. (2015) High Mobility Group Box Protein 1 (HMGB1): The Prototypical Endogenous Danger Molecule. Mol. Med. 21 Suppl 1: S6-S12.

38. Zhang G, et al. (2009) Lipopolysaccharide stimulates platelet secretion and potentiates platelet aggregation via TLR4/MyD88 and the cGMP-dependent protein kinase pathway. J. Immunol. 182:7997-8004

39. Semple JW, Italiano JE, Jr., Freedman J. (2011) Platelets and the immune continuum. Nat Rev Immunol 11:264-74.

40. van der Poll T, Opal SM. (2008) Host-pathogen interactions in sepsis. The Lancet. Infect.ious diseases 8:32-43.

41. Levi M, Keller TT, van Gorp E, ten Cate H. (2003) Infect.ion and inflammation and the coagulation system. Cardiovasc Res 60:26-39.

42. Shorr AF, et al. (2006) Protein C concentrations in severe sepsis: an early directional change in plasma levels predicts outcome. Crit Care 10: R92.

43. Dellinger RP, et al. (2013) Surviving sepsis campaign: international guidelines for management of severe sepsis and septic shock: 2012. Critical care medicine 41:580-637.

44. Jeong YI, et al. (2009) The novel role of platelet-activating factor in protecting mice against lipopolysaccharide-induced endotoxic shock. PLoS One 4: e6503.

45. Friggeri A, et al. (2011) Participation of the receptor for advanced glycation end products in efferocytosis. J. Immunol. 186:6191-8.

46. Chen G, et al. (2004) Bacterial endotoxin stimulates macrophages to release HMGB1 partly through CD14- and TNF-dependent mechanisms. J. Leukoc. Biol. 76:994-1001.

47. Levi M, Ten Cate H. (1999) Disseminated intravascular coagulation. The New England journal of medicine 341:586-92.

48. Gentry CA, Gross KB, Sud B, Drevets DA. (2009) Adverse outcomes associated with the use of drotrecogin alfa (activated) in patients with severe sepsis and baseline bleeding precautions. Critical care medicine 37:19-25.

49. Iba T, Nagaoka I, Boulat M. (2013) The anticoagulant therapy for sepsis-associated disseminated intravascular coagulation. Thrombosis research 131:383-9.

50. Ranieri VM, et al. (2012) Drotrecogin alfa (activated) in adults with septic shock. The New England journal of medicine 366:2055-64.

51. Romisch J, Seiffge D, Reiner G, Paques EP, Heimburger N. (1991) In-vivo antithrombotic potency of placenta protein 4 (annexin V) Thrombosis research 61:93-104.

52. Hotchkiss RS, Monneret G, Payen D. (2013) Sepsis-induced immunosuppression: from cellular dysfunctions to immunotherapy. Nat Rev Immunol 13:862-74.

53. Hotchkiss RS, Nicholson DW. (2006) Apoptosis and caspases regulate death and inflammation in sepsis. Nat Rev Immunol 6:813-22.
Cite this article as: Park JH, et al. (2016) Annexin A5 increases survival in murine sepsis model by inhibiting HMGB1-mediated proinflammation and coagulation. Mol. Med. 22:424-36. 